\title{
DESIGN OF SPECIALIZED SURGICAL SCREW INSERTED IN PLATE TYPE CERVICAL IMPLANT
}

\author{
Krasimira Dimova ${ }^{1}$, Georgi Todorov ${ }^{2}$, Yavor Sofronov ${ }^{3}$
}

\begin{abstract}
In the field of Implantology the screws are an important part because they transfer the loads that occur in the bones. Surgical screws are similar to those in Mechanical Engineering, but the materials should have specific characteristics like biocompatibility, strength, corrosion resistance and fatigue strength. The main function of the surgical screw is to create pressure between two bones which is necessary in order to heal the injured bones. The surgical screw transforms all forces of the movements to pressure and distributes the pressure on the bone's surfaces. Surgical screws can help in the setting of implants into an injured area. It also ensures static position of the injured bones. The research aims to analyse how the surgical screw type affects the bone of the patient with the help of the Finite Elements Method (FEM). Based on the results from the analysis of the surgical screw a new specialized surgical screw was designed with complex geometry to withstand the occurring loads and also be able to transfer them to the bone tissue. In additional, a comparison analysis between two different types of surgical screws was conducted. This paper shows how a surgical screw could be optimized in order to improve its function with the help of virtual tools. Finally, the materials used are biocompatible and often used for such screws and surgical implant analysis, the challenge was to recreate the bone tissue properties and to used them in the FEM analysis.
\end{abstract}

UDC Classification: 621.8, DOI: https://doi.org/10.12955/pns.v2.146

Keywords: cervical implant, FEM analysis, surgical screw, ANSYS analysis, implementation

\section{Introduction}

Virtual and physical prototyping are fast developing as active research areas that integrate basic engineering principles in a medical environment for solving complex problems in the human body. Physical prototyping could be accomplished with additive technology - the technology of 3D printing. In certain clinical cases, this technology is very suitable for creating patient-specific implants, and it is possible to select a suitable material for 3D printing which is biocompatible (Todorov \& Kamberov 2017). The structure of the commonly used surgical screws is like a normal screw with a head and a body. The right choice of surgical screw affects the healing of the bones. The bone type and thickness are the main parameters for the choice of screw type. Also, the pitch of the thread affects the anchorage (Cornelius et al. 2016). The main parameters for choosing the surgical screw are the following: bone type, screw type, diameter of the screw, material of the screw, length of screw and the type of screw head. For the aims of the research a screw is designed with variable pitch and conical part. Also, a comparison analysis is made between a surgical screw and the one designed in this study with the help of FEA and ANSYS software. A torque on the screw's head is applied simulating the fastening of the screw to the bone. The analysis was held for both cases with the same boundary conditions.

\section{Methods}

In the process of designing a patient-specific cervical plate type implant with screws a static-structural analysis were held via FEM with ANSYS (Semkov \& Dimova 2020). The main purpose of the surgical screw is to redistribute the load in a way that does not harm the bones. One of the parameters which influence the screw choice is the bone type. In this parameter there is cortical bone, a dense tissue and trabecular bone, a porous tissue. Another main parameter is screw type and diameter, which have a direct impact on the tools used and friction force. Practically the first pitches of the thread are distributing a huge part of the load.

Also, the screw's thread is an important parameter because of the bone-screw relation that could endanger the surrounding bone due to its thread design. The nominal screw length is an essential parameter and must be chosen correctly. Too short screws will not provide sufficient force. Too long screws can cause soft tissue problems or be noticeable. In the current case, the screw must not pass through the vertebrae because there is a risk of nerve or spinal cord injury. For the examined case a CT scan of a patient's spine was used, from which was made a 3D model of the vertebrae (Todorov et al., 2018, Kamberov et al., 2020). The research is example of the Virtual tools appliance.

For the aims of the study surgical screw M 2,7 (Figure 1) was used on which a torque of $1 \mathrm{Nm}$ (Figure 3 ) is applied simulating the fastening of the screw to the bone (International Organization for

\footnotetext{
${ }^{1}$ Faculty of Industrial technologies, Technical university of Sofia, Bulgaria, krdimova@tu-sofia.bg

${ }^{2}$ Faculty of Industrial technologies, Technical university of Sofia, Bulgaria, gdt@tu-sofia.bg

${ }^{3}$ Faculty of Industrial technologies, Technical university of Sofia, Bulgaria, ysofronov@tu-sofia.bg
} 
Standardization, 1991). Part of the vertebrae where the screw is inserted is also part of the simulation. Different material characteristics are defined for those parts. The boundary conditions for the analysis are frictional contact between the screw's body and the bone as the frictional coefficient is 0.2 , which defines the analysis as non-linear. The boundary conditions are the following: on the two sides of the bone is removed the translation of the $\mathrm{Y}$ axis and for the other two it is removing the translation of the $\mathrm{X}$ axis. The generated mesh consists of 46456 nodes and 247450 elements (Figure 2). As result Von Mises Stress is more than the Yield strength for the bone, which is $145 \pm 8 \mathrm{MPa}$ and the deformations aren't well distributed (Landolt, 2007). Also, the von-Mises stress is increased in the area in the screw's top, where there is risk to break the bone, which is the worst scenario.

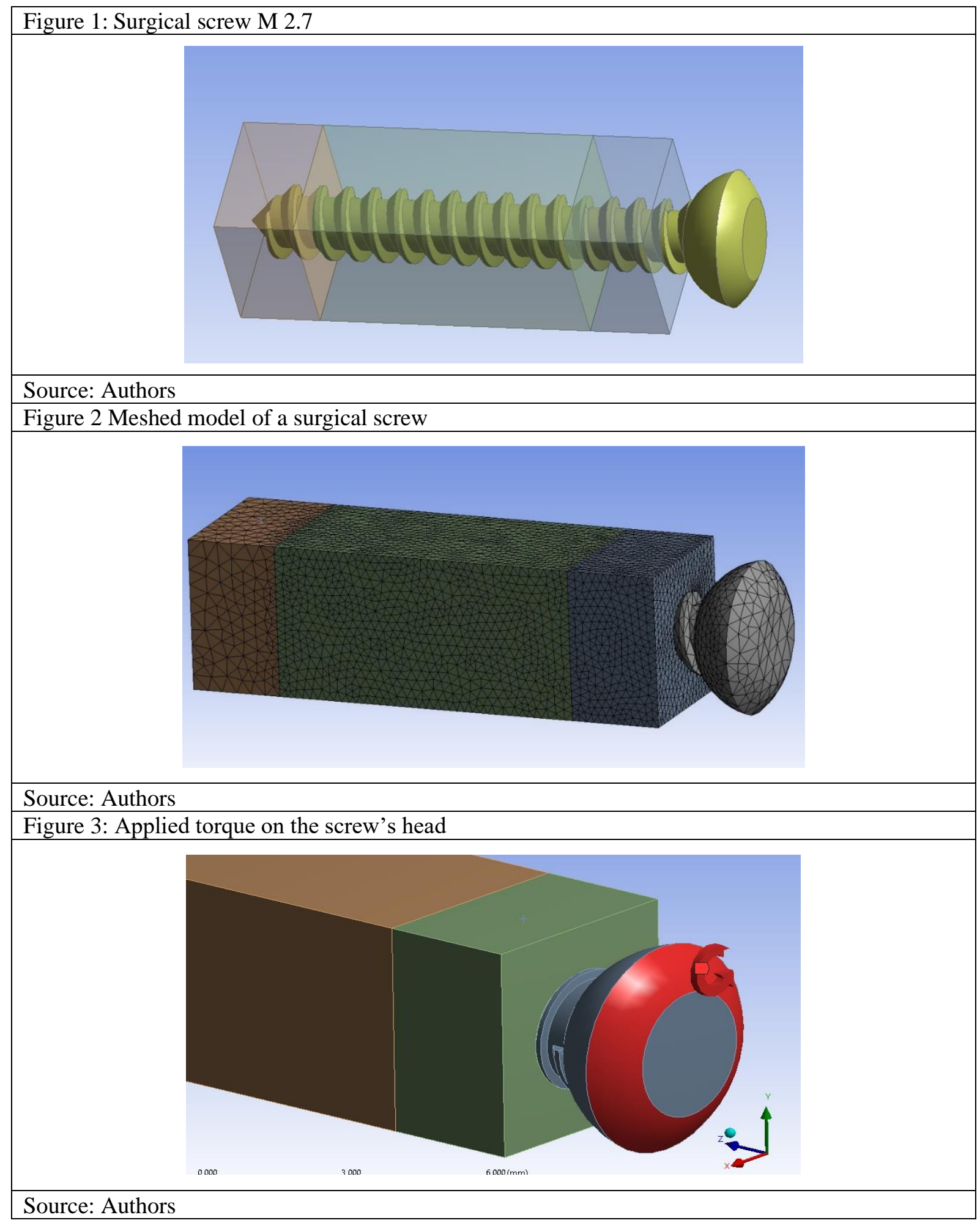




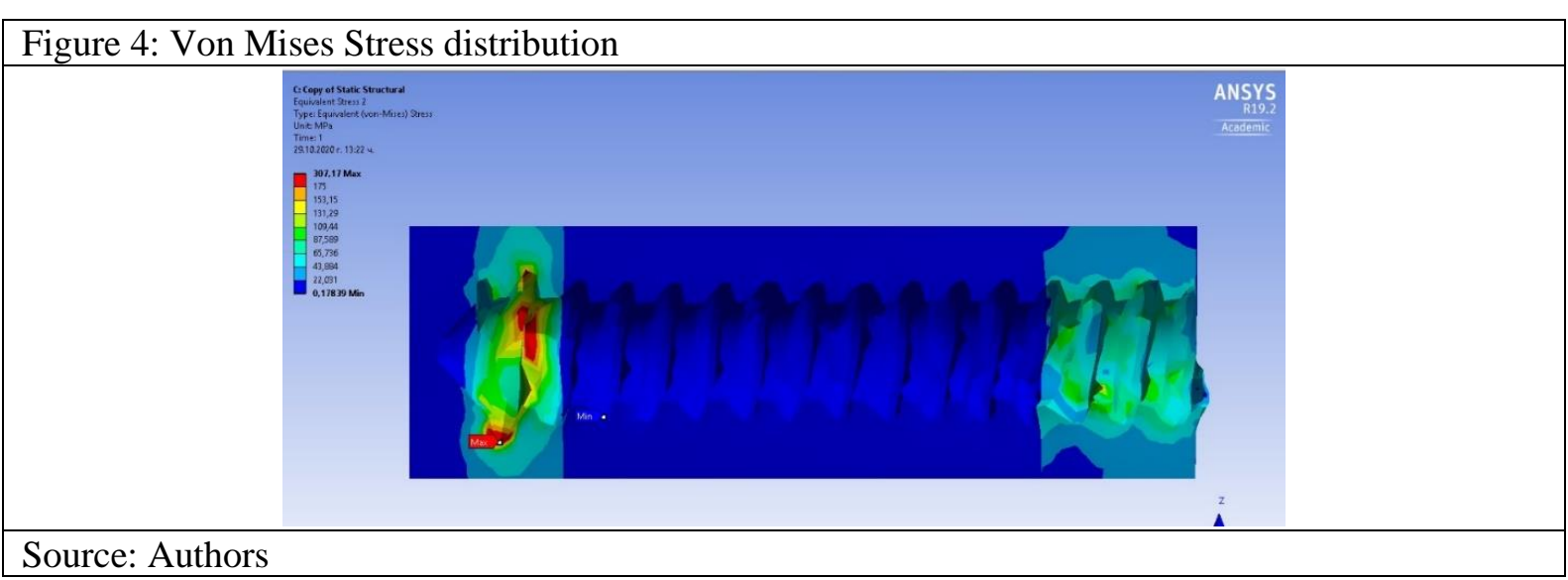

The results are not satisfying because there is risk to break the bone, so a new screw is designed with variable pitch and a conical part of the body to ensure better load distribution (Figure 5) (Figure 6). The idea is to ensure a bigger contact area in the part of the vertebrae where the bone is cortical which has better material properties than the trabecular bone. The new screw has a fine thread pitch and a conical part in the cortical area. The finite element analysis was held with the new screw. The boundary conditions and the applied torque was the same for the analysis. The number of nodes were 230557 and the number of elements were 1317251 (Figure 7).

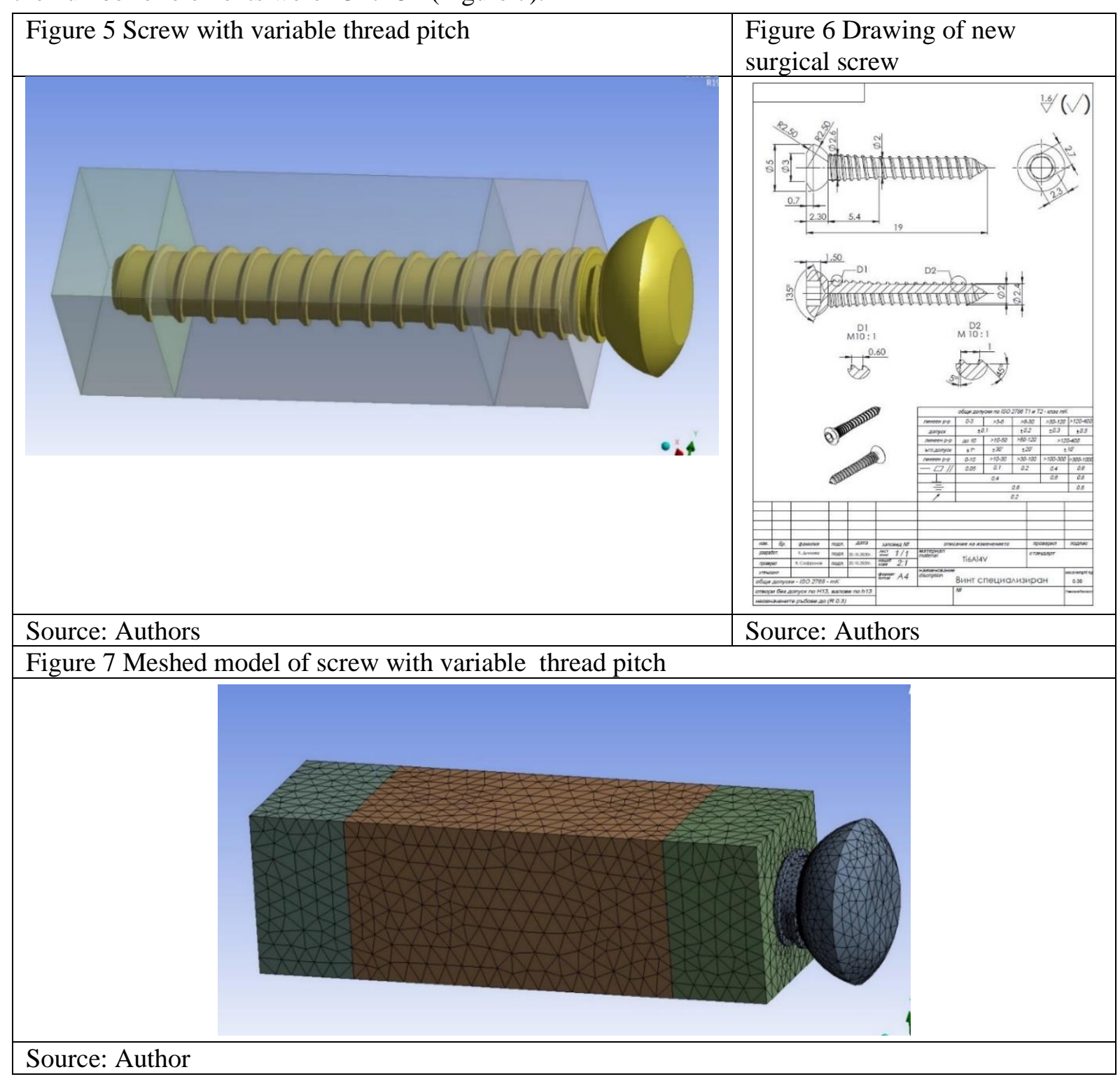




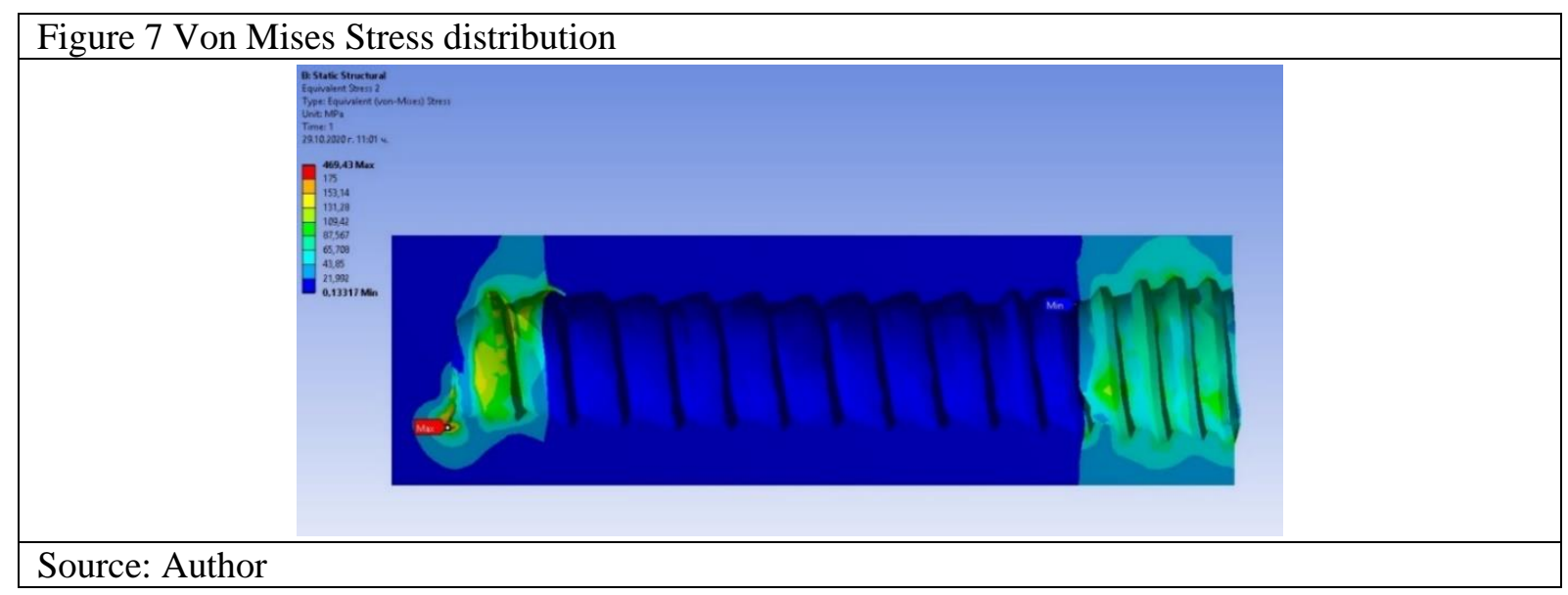

As result the deformations are well distributed, and the von Mises Stress is less than the Yield strength except in the node exceeding the stress (Figure 7). When comparing both cases. it can be concluded that the new screw's design improves the stress distribution.

\section{Materials}

For the aims of the research material characteristics were defined like Poisson's ratio, density, Young Modulus for the bone and it is chosen titanium alloy (Ti6Al4V) for the screw. Most metals and alloys which are corrosion-resistant are known also as passive metals because they are in passive state, which means they have a thin oxide layer, in the current case, $\mathrm{a} \mathrm{TiO}_{2}$ layer on the surface, which protects the metal from the environment (Landolt, 2007) Usually, the thickness of the oxide layer of those passive metals is about 3-10 $\mathrm{nm}$ (Neoh, Hu, Zheng et al., 2012). The fact is that this oxide layer gives an advantage in the process of implants integration although it is dependent on the thickness of the passive film. The effect of the $\mathrm{TiO}_{2}$ wasn't included in the simulations.

In order to have a more accurate analysis the specific vertebrae material characteristics are defined too. The anatomy of the vertebrae consists of cortical bone and trabecular bone on the inside of the vertebrae, which is also observed in the finite element model. The materials used in Implantology must be biocompatible, resistant, strong and not cause any skin irritation. Only few materials match the requirements. Titanium and titanium alloys are one of these materials. Table 1 shows the material characteristics of the cortical bone, trabecular bone and titanium alloy (De Viteri \& Fuentes, 2013).

\begin{tabular}{|llll|}
\hline \multicolumn{2}{|l|}{ Table 1: Material characteristics } & & \\
\hline Material & Young Modulus [GPa] & Poisson's ratio & Density $[\mathbf{k g} / \mathbf{m} 3]$ \\
Cortical bone & 17 & 0.3 & 2000 \\
Trabecular bone & 0.35 & 0.25 & 234 \\
Ti6Al4V & 114 & 0.35 & 4430 \\
\hline Source: Material Property & Data, Mat Web & & \\
\hline
\end{tabular}

\section{Results}

The main outcome of the research was investigated and an analysis of the surgical screw in working conditions was conducted. The main parameters which influence surgical screw choice were observed especially when considering the type of thread. As a result of our analysis, an improved design of a surgical screw with optimised geometry in order to ensure better anchoring was introduced.

\section{Discussion}

The research presents an optimized design of a surgical screw with variable thread pitch and a conical part to ensure better load distribution compared to a surgical screw according to the results of the analysis. The results indicate that the design of a surgical screw could be improved by developing the complex geometry with variable thread pitch and a conical part. The design and the analysis were made with the help of virtual tools, the next step of the research will include rapid prototyping of the surgical screw. Further tests are needed following the Standard Test Methods for Spinal Implant Constructs in a Vertebrectomy Model which includes static and dynamic axial compression, static torsion and static tension (ASTM, 2018). 


\section{Conclusion}

With the help of Virtual Prototyping, a new surgical screw was designed which has better load distribution. Based on ANSYS FEM analysis a comparison was made between a surgical screw and our own designed screw. To summarize by designing the screw's thread with variable pitch and adding a conical part on the side of the screw's head better load and stress distribution was achieved. The research is a step forward in the field of innovation connected to Human health and Mechanical engineering. Uniting the work of engineers and surgeons into the field of Implantology while also using technologies for 3D modelling and FEA software give us results such as our own designed surgical screw.

\section{Acknowledgement}

This study is performed by the support of project DN-17-23 "Developing an approach for bone reconstruction and implant manufacturing through virtual engineering tools" of National Science Fund, Ministry of Education and Science, Bulgaria.

\section{References}

ASTM-American Society for Testing and Materials. (2018). Spine corpectomy model ASTM F1717. Retrieved from Standart Test Methods for Spinal Implant Construct in a Vertebrectomy Model: https://tinyurl.com/9e58eyv4

Cornelius,C., Gellrich, N., Hillerup, S., Kusumoto, K., Schubert, W. (2016). Choice of implants. Retrieved from https://surgeryreference.aofoundation.org/cmf/trauma/midface/further-reading/choice-of-implants\#introduction

International Organization for Standardization (1991). Implants for surgery - Metal bone screws with hexagonal drive connection, spherical under-surface of head, asymmetrical thread - Dimensions. Retrieved from ISO 5835(en): https://www.iso.org/obp/ui/fr/\#iso:std:iso:5835:ed-1:v1:en

Kamberov, K., Todorov, G., Sofronov, Y., Nikolov, N. (2020). Methodology for designing, manufacturing and integration of personalized spinal implants for surgical treatment of the cervical spine. 46 Conference "Applications of Mathmatics in Technics and Economics"-AMEE, 2333, pp 1100091-1100095 (https://doi.org/10.1063/5.0042381),

Landolt, D. (2007). Corrosion and Surface Chemistry of Metals. New York: EPFL Press, https://doi.org/10.1201/9781439807880

Neoh, K., Hu,X., Zheng, D., Kang, E..(2012). Balancing osteoblast functions and bacterial adhesion on functionalized titanium surfaces. doi: 10.1016/j.biomaterials.2012.01.018.

De Viteri, V., Fuentes, E. (2013). Titanium and Titanium Alloys as Biomaterials. Retrieved from Intechopen: https://www.intechopen.com/chapters/44858

Semkov, M., Dimova, K. (2020). Comparison of Stress distribution on Periodontally Compromised Mobile Teeth splinted and non-splinted using Finite Element Method. 46 Conference "Applications of Mathmatics in Technics and Economics"AMEE, 2333, pp 110010-1-110010-6 (DOI:10.1063/5.0044796).

Todorov, G., Kamberov, K. (2017). Virtual engineering. Sofia: Direct Services Ltd, ISBN 978-619-7171-15-0.

Todorov, G., Nikolov, N., Sofronov, Y., Gabrovsky, N., Laleva, M., Gavrilov, T. (2018). Computer Aided Design of Customized Implants Based On Ct-Scan Data and Virtual Prototypes. Future Access Enablers for Ubiquitous and Intelligent Infrastructures, pp. 339-346. 